\title{
Rapid diagnostics for influenza: what are the options?
}
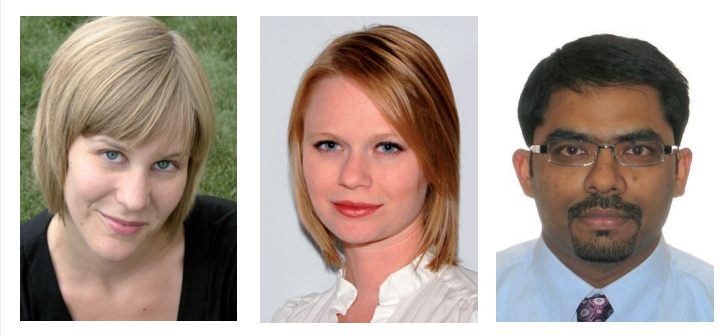

"Early identification of

influenza as the cause of

an acute febrile

respiratory illness is

important for optimal

patient management..."

\section{Caroline Chartrand ${ }^{1,2}$, Jessica Minion ${ }^{1,3}$ \& Madhukar Pai ${ }^{\dagger 1}$}

'Department of Epidemiology \& Biostatistics, McGill University \& Montreal Chest Institute, Montreal, Canada 2Department of Pediatrics, Sainte-Justine Hospital, Montreal, Canada

${ }^{3}$ Department of Medical Microbiology \& Immunology, University of Alberta, Edmonton, Canada

${ }^{\dagger}$ Author for correspondence: McGill University, Department of Epidemiology \& Biostatistics, 1020 Pine Avenue

West, Montreal, QC H3A 1A2, Canada = Tel.: + 15143985422 - Fax: +1 5143984503 - madhukar.pai@mcgill.ca

Worldwide, influenza occurs in yearly epidemics. Although the vast majority of infected individuals exhibit a self-limited, acute febrile illness or are asymptomatic, influenza can cause significant morbidity and mortality. In the USA, influenza is responsible for over 200,000 hospitalizations annually and an average of 36,000 individuals die each year of influenza-related causes [1,2] . Moreover, influenza A virus has the potential to create global pandemics, as illustrated by the recent $2009 \mathrm{H} 1 \mathrm{~N} 1$ pandemic, which affected more than 214 countries and was responsible for more than 18,000 deaths, likely to be an underestimate since many were never tested for influenza [101].

Early identification of influenza as the cause of an acute febrile respiratory illness is important for optimal patient management by allowing more appropriate use of outpatient services and ancillary tests, prompt institution of infection control measures and timely administration of antiviral treatment. Current antiviral treatments for influenza have been shown to be effective in reducing severity, duration of illness and complications, but they should be started within $48 \mathrm{~h}$ of symptoms onset [3]. Since most patients are likely to present for medical care towards the end of this time frame, it leaves the clinician with a very narrow window of opportunity to establish the correct diagnosis and start antiviral treatment in high-risk patients. However, a clinical diagnosis of influenza is difficult because of the cocirculation of other virus (respiratory syncytial viruses, adenovirus, rhinovirus, parainfluenza) and bacterial agents (Chlamydophila pneumoniae, Mycoplasma pneumoniae, Streptococcus pneumoniae and Legionnella sp.) that can produce similar symptoms. The case definition of influenza-like illness, defined as fever and cough or sore throat, has a sensitivity of $64 \%$ and a specificity of $67 \%$ [4], only slightly better than a coin toss. For this reason, clinicians often turn to laboratory diagnostic tools when the diagnosis of influenza is likely to impact patient management.

There are three main types of diagnostic test for influenza: virus isolation in cell culture, detection of influenza-specific RNA and direct antigen detection. Viral culture is the time-honored gold standard of influenza diagnosis and provides essential virologic data on strain characteristics, such as antiviral susceptibility and relatedness to vaccine strains, while monitoring for the emergence of novel influenza strains. However, it is of little use for patient management since results may take 3-10 days, though shell vial culture, in which specimens are centrifuged on a monolayer of cells, can provide results in $48 \mathrm{~h}$ [3]. Reversetranscriptase PCR, which detects relatively stable matrix genes in the influenza RNA, is the most sensitive and specific test for influenza. It is also the most expensive and least widely available test and, since samples are usually run in batches, it usually takes more than the theoretically possible 4-6 h turn-around time for clinicians to receive the test results [3]. The last of the conventional influenza tests is immunofluorescence, which detects influenza antigens in clinical specimens through fluorescent antibody staining. Although results are available in $2-4 \mathrm{~h}$, this test depends heavily on laboratory expertise and is usually not conducted outside of regular laboratory hours [3], limiting its usefulness in a 24/7 healthcare system.

None of the abovementioned conventional influenza diagnostic tests are able to provide a timely answer to the physician's question 'Does

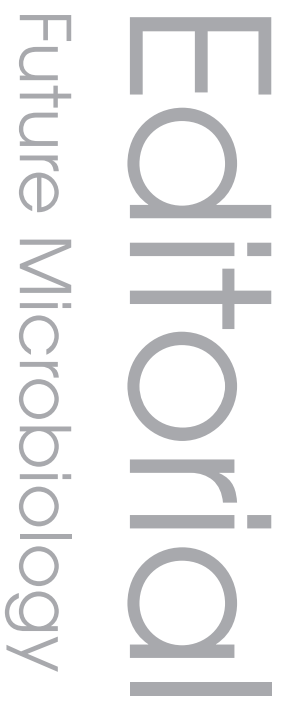

Keywords

- diagnostics = influenza

- point-of-care test $m$ rapid test - RIDT $=$ test accuracy

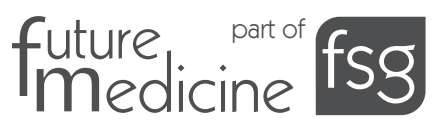


"None of the ... conventional influenza diagnostic tests are able to provide a timely answer to the physician's question 'Does my patient have influenza?" my patient have influenza?' This has spurred the development of an array of commercial rapid influenza diagnostic tests (RIDTs) that give results in $15-30 \mathrm{~min}$, are simple to use and can, in some cases, be used at the pointof-care (POC). The majority of these tests are immunoassays that detect specific influenza viral antigens in respiratory specimens. These antigens are usually nucleoproteins, the internal structural proteins of influenza viruses, which differ between influenza $A$ and $B$ but tend to be conserved among A or B strains (Figure 1) [5]. However, one test (ZstatFlu-II test) detects viral neuraminidase activity through its catalysis of a chemical reaction [102].
In general, RIDTs can either detect influenza A only, or detect influenza A and B but not distinguish between the two, or detect influenza A and B and distinguish between them. However, none of these tests can differentiate influenza A subtypes and so can't distinguish between seasonal influenza and $2009 \mathrm{H} 1 \mathrm{N1}$, for example. A RIDT usually gives a dichotomous yes/no answer by means of a color change. If a color change is only detected at the control position, the test is negative. If a color change is visible at the control and influenza A or B position, the test is positive (FIGURE 1). According to most manufacturers, even a very faint color change should be considered positive and this is

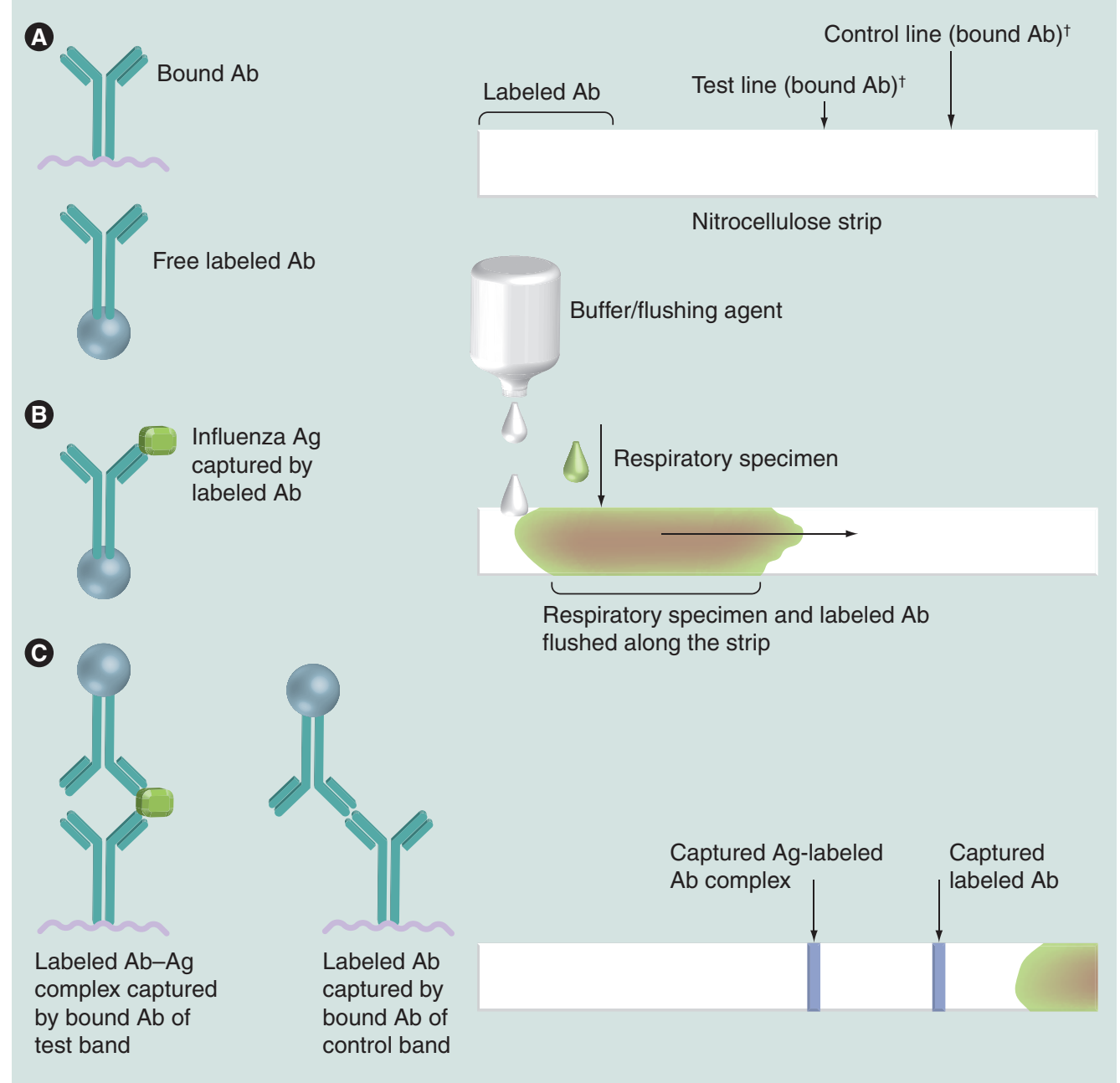

Figure 1. Mode of action of influenza rapid diagnostic tests. (A) Dye-labeled free Abs, specific for the target antigen, are present on the lower end of the nitrocellulose strip. Abs, also specific for the target antigen, are bound to the strip in a thin test line and Abs specific for the dye-labeled Abs are bound to the control line. (B) Respiratory specimen and buffer are added to the strip and mix with the dye-labeled free Abs. They are drawn up the strip, across the two lines of bound Abs.

(C) If influenza antigen are present, some of the dye-labeled Abs will be trapped on the test line. Other dye-labeled Abs are trapped on the control line.

Ab: Antibody; Ag: Antigen.

${ }^{\dagger}$ Not normally visible.

Reproduced with permission from [5]. 
where experience might come into play in the interpretation of these tests. If no color change occurs at the control position, the test is considered invalid, regardless of any color change at the influenza $\mathrm{A}$ or $\mathrm{B}$ position.

A vast array of different RIDTs are available with different characteristics and variable accuracy (the most frequently used or researched tests are listed in Table 1). Because these assays were widely used during the 2009 H1N1 pandemic, clinicians and healthcare providers need to understand their strengths and limitations better. Strengths include simplicity, rapidity, potential for POC use and likely impact on clinical decisions and ability to influence patient outcomes. The cost of RIDTs, which is US\$15-20 per test for kit and reagent [6], is also less than the cost of conventional laboratory-based influenza tests such as RT-PCR and viral culture.

The biggest limitation of current RIDTs is their accuracy. Because of their relatively low sensitivity (median of 70-75\%) [102], false negative results have been held as a major concern when using RIDTs. However, their high specificity (median of 90-95\%) [102] makes false positive results unlikely and a positive RIDT should be sufficient to institute appropriate treatment or infection control measures. Both the WHO and the Infectious Disease Society of America rank RIDTs third, after RT-PCR and immunofluoresence, in their recommendations of tests for the diagnosis of influenza but recognize their potential utility in the management of patients and outbreaks when the other tests are not readily available $[3,5]$. The US Centers for Disease Control has given RIDTs a more complete endorsement for the diagnosis of seasonal influenza, stating that "a rapid influenza test or immunofluorescence are the tests of choice to help with decision to use antiviral medication" [103].

The fact that some RIDTs are approved for use outside of regulated laboratories does not alleviate all of the concerns associated with having these tests performed in clinical settings. Most evaluations of RIDTs have been performed by laboratory technologists, or at the

Table 1. Profile of commonly used influenza rapid tests.

\begin{tabular}{|c|c|c|c|c|c|c|c|c|}
\hline Manufacturer & Test & $\begin{array}{l}\text { CLIA } \\
\text { status }^{\dagger}\end{array}$ & $\begin{array}{l}\text { Distinguish } \\
\text { between } \\
\text { influenza A } \\
\text { and B? }\end{array}$ & $\begin{array}{l}\text { Acceptable } \\
\text { specimens }\end{array}$ & $\begin{array}{l}\text { Assay } \\
\text { time }\end{array}$ & Sensitivity & Specificity & Ref. \\
\hline \multirow[t]{2}{*}{$\begin{array}{l}\text { Inverness Medical } \\
\text { (ME, USA) }\end{array}$} & $\begin{array}{l}\text { BinaxNOW }{ }^{\circledR}, \\
\text { Influenza }\end{array}$ & $\begin{array}{l}\text { CLIA } \\
\text { waived }\end{array}$ & Yes & $\begin{array}{l}\text { NS, NA, NW, } \\
\text { NPS }\end{array}$ & $15 \min$ & $\begin{array}{l}\text { A: } 78-82 \% \\
\text { B: } 58-71 \%\end{array}$ & $\begin{array}{l}\text { A: } 92-94 \% \\
\text { B: } 97 \%\end{array}$ & [102] \\
\hline & $\begin{array}{l}\text { BinaxNOW }^{\circledR}, \\
\text { Influenza A \& B }\end{array}$ & $\begin{array}{l}\text { CLIA } \\
\text { waived }\end{array}$ & Yes & $\begin{array}{l}\text { NS, NA, NW, } \\
\text { NPS }\end{array}$ & $15 \mathrm{~min}$ & $\begin{array}{l}\text { A: } 77-83 \% \\
\text { B: } 50-59 \%\end{array}$ & $\begin{array}{l}\text { A: } 96-99 \% \\
\text { B: } 100 \%\end{array}$ & {$[7,102]$} \\
\hline $\begin{array}{l}\text { Becton Dickinson } \\
\text { (NJ, USA) }\end{array}$ & $\begin{array}{l}\text { Directigen }^{\mathrm{TM}} \\
\text { Flu } A+B\end{array}$ & $\begin{array}{l}\text { CLIA } \\
\text { moderate }\end{array}$ & Yes & $\begin{array}{l}\text { NS, NPS, NPA, } \\
\text { NPW, TS, BAL }\end{array}$ & $15 \min$ & $\begin{array}{l}\text { A: } 77-96 \% \\
\text { B: } 71-88 \%\end{array}$ & $\begin{array}{l}\text { A: } 90-99.6 \% \\
\text { B: } 97-100 \%\end{array}$ & {$[8,102]$} \\
\hline Biostar Inc. (CO, USA) & Flu OIA ${ }^{\circledR}$ & $\begin{array}{l}\text { CLIA } \\
\text { waived }\end{array}$ & No & $\begin{array}{l}\text { NA, NPS, TS, } \\
\text { sputum }\end{array}$ & $20 \mathrm{~min}$ & $62-88 \%$ & $52-80 \%$ & {$[102]$} \\
\hline Quidel (CA, USA) & $\begin{array}{l}\text { QuickVue } \\
\text { Influenza A+B }\end{array}$ & $\begin{array}{l}\text { CLIA } \\
\text { waived }\end{array}$ & Yes & $\begin{array}{l}\text { NS, NA, NW, } \\
\text { NPS }\end{array}$ & $10 \mathrm{~min}$ & $\begin{array}{l}\text { A: } 72-94 \% \\
\text { B: } 62-82 \%\end{array}$ & $\begin{array}{l}\text { A: } 90-99 \% \\
B: 96-99 \%\end{array}$ & {$[9,102]$} \\
\hline $\begin{array}{l}\text { Standard Diagnostic } \\
\text { Inc. (South Korea) }\end{array}$ & $\begin{array}{l}\text { SD BIOLINE } \\
\text { influenza Ag Test }\end{array}$ & & Yes & $\begin{array}{l}\text { NS, NA, NPS, } \\
\text { NPA, TS }\end{array}$ & $10 \mathrm{~min}$ & $91.8 \%$ & $98.9 \%$ & [10] \\
\hline Remel Inc. (KS, USA) & XPECT Flu ${ }^{\circledR}$ A\&B & $\begin{array}{l}\text { CLIA } \\
\text { moderate }\end{array}$ & Yes & $\begin{array}{l}\text { NW, NPS, TS, } \\
\text { sputum, } \\
\text { tracheal } \\
\text { aspirate, BAL }\end{array}$ & $15 \mathrm{~min}$ & $\begin{array}{l}\text { A: } 89-100 \% \\
\text { B: } 93-100 \%\end{array}$ & $\begin{array}{l}\text { A: } 100 \% \\
\text { B: } 100 \%\end{array}$ & {$[11,102]$} \\
\hline Zyme Tx Inc. (OK, USA) & ZstatFlu-II test & $\begin{array}{l}\text { CLIA } \\
\text { waived }\end{array}$ & No & TS & $30 \mathrm{~min}$ & $65-96 \%$ & $77-98 \%$ & {$[12,102]$} \\
\hline \multicolumn{9}{|c|}{$\begin{array}{l}\text { Sensitivity and specificity estimates were derived from package inserts. } \\
\text { 'Clinical Laboratory Improvement Amendment of 1988. CLIA waived tests can be performed in a clinical or office setting. } \\
\text { BAL: Broncho-alveolar lavage; CLIA: Clinical Laboratory Improvement Amendment; NA: Nasal aspirate; NPA: Nasopharyngeal aspirate; NPS: Nasopharyngeal swab; } \\
\text { NPW: Nasopharyngeal wash; NS: Nasal swab; NW: Nasal wash; TS: Throat swab. }\end{array}$} \\
\hline
\end{tabular}




\begin{tabular}{l}
\hline "As long as clinicians are \\
aware that a negative \\
RIDT does not preclude \\
influenza infection in a \\
patient with compatible \\
illness, they are still \\
the best rapid test \\
option available..."
\end{tabular}

least trained clinical personnel conscientious of the need for strict procedural adherence. In practice this may not always be the case, where the demands of busy clinics and emergency departments may result in untrained staff performing and reading the tests and test protocols being followed less rigorously.

Taking into account the potential impact of training clinical staff to perform RIDTs, along with the burden of providing appropriate space to perform the tests and the interruptions they may cause to the clinical work flow, some decision makers may find that it is more practical to have these tests performed in a nearby laboratory by a technologist despite their potential for true POC use. If this is the case, however, the unique benefits of RIDTs will be lost, unless turn-around-times are very short. Indeed, laboratories that find themselves performing RIDTs as a service for clinicians should consider the resources it would require to instead acquire the equipment and skills to offer rapid turnaround immunofluorescent influenza diagnostics. In many smaller settings, this will not be feasible and laboratory-performed RIDTs will be a compromise between POC testing by clinicians and off-site diagnostics with longer turn-around times.

A final question then arises concerning the use of RIDTs: can they be used as a standalone diagnostic, or should all results be confirmed with a second test? Given the relatively high specificity of RIDTs, it is reasonable to take clinical action based on a positive RIDT result. However, if subsequent RT-PCR testing is negative for influenza, should influenza medications and infection control measures be discontinued? The answer to this is likely to depend on both the timeliness of the confirmatory test and the trust one places in the quality of RIDT performance and reading.
Such questions of trust in test performance are notoriously difficult to resolve, especially when POC use brings with it many uncontrolled variables. Similarly, will all negative RIDT results require subsequent screening with a more sensitive test, such as RT-PCR? In most cases, given the only modest sensitivity of RIDTs, the answer to this question will be yes. However, there may be some settings where the potential impact to clinical decision making is the sole goal of RIDT implementation and delayed positive detection will not result in follow-up and further management and will not be used for surveillance. These details should be considered carefully and in consultation with local diagnostic laboratories and hospital infection control committees when deciding if and how to add RIDTs to the toolbox for investigating acute febrile respiratory illness.

Despite their shortcomings, RIDTs are probably here to stay. As long as clinicians are aware that a negative RIDT does not preclude influenza infection in a patient with compatible illness, they are still the best rapid test option available to clinicians to concretely impact on patient management, because of the delay involved in obtaining results from any other laboratory-based influenza diagnostic tests.

\footnotetext{
Financial \& competing interests disclosure

The authors have no relevant affiliations or financial involvement with any organization or entity with a financial interest in or financial conflict with the subject matter or materials discussed in the manuscript. This includes employment, consultancies, honoraria, stock ownership or options, expert testimony, grants or patents received or pending, or royalties.

No writing assistance was utilized in the production of this manuscript.
}

\section{Bibliography}

1. Thompson WW, Shay DK, Weintraub E et al: Influenza-associated hospitalizations in the United States. JAMA 292, 1333-1340 (2004).

2. Thompson WW, Shay DK, Weintraub E et al.: Mortality associated with influenza and respiratory syncytial virus in the United States. JAMA 289, 179-186 (2003).

3. Harper SA, Bradley JS, Englund JA et al:: Seasonal influenza in adults and children diagnosis, treatment, chemoprophylaxis, and institutional outbreak management: Clinical
Practice Guidelines of the Infectious Diseases Society of America. Clin. Infect. Dis. 48, 1003-1032 (2009).

4. Call SA, Vollenweider MA, Hornung CA et al:: Does this patient have influenza? JAMA 293, 987-997 (2005).

5. World Health Organization: Use of influenza rapid diagnostic tests. special programme for research and training in tropical diseases (TDR). WHO Press, Geneva, Switzerland (2010).

6. Rapid diagnostic tests for influenza. Med. Lett. Drugs Ther. 41, 121-122 (1999).
7. BinaxNOW ${ }^{\circledR}$, Influenza A \& B, package insert. Binax Inc., ME, USA (2008).

8. Directigen ${ }^{\mathrm{TM}}$ Flu $\mathrm{A}+\mathrm{B}$, package insert. Becton Dickinson, NJ, USA (2006).

9. QuickVue ${ }^{\circledR}$ Influenza $A+B$, package insert. Quidel, CA, USA (2009).

10. SD BIOLINE influenza Ag Test, package insert. Standard Diagnostic Inc., Giheungeup Yongin-si Gyeonggi-do, Korea (2007).

11. XPECT ${ }^{\circledR}$ Flu $A \& B$, package insert. Remel Inc., KS, USA (2003).

12. ZstatFlu ${ }^{\mathrm{TM}}$, package insert. ZymeTx Inc., OK, USA. 


\section{Websites}

101. World Health Organization. Pandemic (H1N1) 2009 - update 109 www.who.int/csr/don/2010_07_16/en/index. html

(Accessed 22 July 2010)
102. World Health Organization: WHO recommendations on the use of rapid testing for influenza diagnosis (July 2005) www.who.int/csr/disease/avian_influenza/ guidelines/rapid_testing/en (Accessed 22 July 2010)
103. Center for Disease Control and Prevention: Interim guidance for influenza diagnostic testing during the 2008-2009 influenza season (1 August 2009) www.cdc.gov/flu/professionals/ diagnosis/0809testingguide.htm (Accessed 22 July 2010) 